\title{
ANALISIS KEBERLANJUTAN USAHATANI GAMBIR DALAM MENDUKUNG KOMODITI UNGGULAN LOKAL DI KABUPATEN LIMA PULUH KOTA
}

\section{SUSTAINABILITYANALYSIS OF SMALLHOLDER GAMBIER TO SUPPORTING LOCAL LEADING COMMODITIES IN THE DISTRICT 50 KOTA}

\author{
Elviati* $^{1}$ ), Ardi Sardina Abdullah ${ }^{1}$ ), Syafrison $^{2}$ ), Fardedi $^{2}$ ), Mismawarni Srima Ningsih ${ }^{2}$ ) \\ 1) Program Studi Pengelolaan Perkebunan Jurusan Budidaya Tanaman Perkebunan, \\ Politeknik Pertanian Negeri Payakumbuh \\ 2) Program Studi Budidaya Tanaman Perkebunan Jurusan Budidaya Tanaman \\ Perkebunan, Politeknik Pertanian Negeri Payakumbuh \\ elviatidarwis25@gmail.com
}

\begin{abstract}
ABSTRAK
Komoditi gambir merupakan salah satu komoditi tanaman perkebunan yang masih punya cukup peran dalam perdagangan internasional. Peningkatan produktifitas dan perdagangan luar negeri ini tidak sebanding dengan peningkatan pendapatan petani gambir. Agar produktifitas dapat ditingkatkan maka mutu olahan juga perlu di perbaiki agar tersedia pasar yang akan menampung produk gambir petani.Peningkatan pendapatan petani gambir belum sejalan dengan peningkatan produktivitas dan luas lahan, hal ini berkaitan dengan persoalan pasar yang masih mendominasi dari beberapa persoalan usahatani gambir, sehingga akan menyebabkan berkurangnya minat petani dalam melakukan usahatani gambir. Oleh sebab itu peneliti tertarik melakukan penelitian dengan fokus pada keberlanjutanusahatani gambir dalam mendukung komoditi unggulan daerah.Penelitian ini dilaksanakan di Kabupaten Lima Puluh Kota, karena merupakan sentra komoditi gambir yang ada di Sumatera Barat dengan, menggunakan metode survey. Penelitian ini dilakukan selama 4 bulan mulai Bulan April sampai Agustus 2021. Hasil penelitian mendapatkan bahwa usahatani gambir belum mendapatkan pasar yang baik.Peran kelembagaan pemasaranbelum memberikan konstribusi dalam meningkatkan posisi tawar, petani hanya bisa menjual gambir pada tingkatan pedagang pengumpul.Pemasaran produk gambir hanya tergantung pada pedagang pengumpul (toke) sehingga petani tidak punya nilai tawar dalam menentukan harga.Analisis usahatani gambir ini tetap memberikan kriteria yang layak di lakukan dengan nilai $\mathrm{R} / \mathrm{C}$ ratio 1,6 .
\end{abstract}

Kata Kunci : Gambir, Pemasaran, Kelembagaan, Pasar internasional, Produktifitas

\section{ABSTRACK}

Gambier commodity is one of the plantation crop commodities which still has quite a role in international trade. This increase in productivity and foreign trade is not comparable to the increase in the income of gambier farmers. In order to increase productivity, the quality of processed products also needs to be improved so that there is a market that will accommodate farmers' gambir products. The increase in the income of gambier farmers has not been in line with the increase in productivity and land area, this is related to market issues that still dominate some of the gambier farming problems, so that it will cause a decrease in farmers' interest in gambier farming. Therefore, researchers are interested in conducting research with a focus on the sustainability of gambier farming in supporting 
regional superior commodities. This research was conducted in Lima Puluh Kota Regency, because it is the center of gambier commodity in West Sumatera by using the survey method. This research was conducted for 4 months from April to August 2021. The results showed that gambier farming has not yet received a good market. The role of marketing institutions has not contributed to improving their bargaining position, farmers can only sell gambier at the level of collectors. Marketing of gambir products only depends on collectors (toke), so that farmers have no bargaining power in determining prices. This gambier farming analysis still provides criteria that are feasible to do with an $R / C$ ratio value of 1.6.

\section{Key Word: Gambier, Marketing, institutional, international market, produktivity}

\section{Pendahuluan}

Gambir merupakan komoditas tanaman perkebunan yang didapat dari getah yang telah di ekstrak dari daun tanaman. Tanaman Gambir ini di gunakan untuk menyirih bagi sebagian masyarakat namun di samping itu gambir mempunyai beberapa fungsi antara lain untuk campuran bahan obat-obatan, penyamak kulit dan pewarna tekstil (Suharman, 2018).

Indonesia merupakan negara pengekspor gambir terbesar di dunia dimana $80 \%$ produksi gambir berasal dari Indonesia, ini merupakan peluang bagi pengembangan tanaman Gambir karena mempunyai peluang pemasaran yang besar yang akan menampung produk. Untuk Sumatera Barat sendiri dapat menyumbang produksi gambir untuk produk nasional sebesar $80 \%$ yang berasal dari daerah Sumatera Barat dan daerah lainnya seperti Aceh, Sumatera Utara, Riau, Sumatera Selatan dan Kalimantan Barat (Suharman, 2018).

Usaha perkebunan gambir dan pengolahannya di lakukan oleh petani gambir dengan rangkaian pembukaan lahan, pembibitan, penanaman, panen dan pengolahan sampai gambir siap jual. Akibatnya mengharuskan petani untuk mengerjakan usaha budidaya dan pengolahan tidak mengalami banyak perubahan, sehingga masih di kerjakan secara tradisonal (Dhalimi, 2006), akibatnya menghasilkan produk dengan kualitas dan efisiensi yang rendah. Sementara hasil penelitian menunjukan tingginya permintaan akan produk gambir di pasar internasional, ini menandakan rendahnya kualitas yang di hasilkan. Sehingga produk dengan mutu yang rendah sulit bersaing dipasar internasional, namun kalau dilihat produk gambir yang dijual petani tidak memperhatikan mutu saat ini petani gambir tidak memisahkan kualitas gambir yang di hasilkan (Yuristia, 2017).

Perbaikan teknologi dalam budidaya gambir di tujukan untuk meningkatkan produktivitas gambir karena hasil penelitian Hosen (2017), menghasilkan bahwa produktivitas gambir petani sangat rendah, namun hal tersebut dapat ditingkatkan melalui teknologi dan sistim pemasaran yang baik. Tidak hanya pasar yang perlu diperbaiki kelembagaan yang terkait dalam pemasaran pun perlu ditingkatkan, Peningkatan kapasitas kelembagaan yang kuat dapat membantu dalam proses transaksi dan pemasaran yang menguntugkan bagi petani gambir (Nasrul, 2019). Oleh karena itu peran kelembagaan ikut menentukan pasar yang memadai bagi produk gambir yang akan dipasarkan petani.

\section{Metodologi Penelitian \\ Tempat dan Waktu}

Penelitian ini dilakukan di Kecamatan Lareh Sago Halaban Kabupaten Lima Puluh Kota yang dipilih dengan sengaja karena merupakan salah satu daerah diKabupaten Lima Puluh Kota yang banyak menghasilkan gambir. Waktu pelaksanaan penelitian ini di lakukan pada bulan April sampai Agustus 2021. 
Metoda Pengambilan Sampel

Jumlah sampel dalam penelitian ini diambil dari sejumlah populasi petani gambir yang berada di Lareh Sago Halaban. Sampel yang ada didaerah penelitian ini berjumlah sebanyak 47 sampel. Sampel ini didapatkan setelah dilakukan kriteria sampel seperti : 1) sampel terdiri dari petani yang mempunyai lahan gambir minimal $0,5 \mathrm{H}, \mathrm{a}$ 2) Selain punya lahan sendiri juga ikut melakukan pengolahan gambir.

\section{Jenis dan Sumber Data}

Data yang dipergunakan dalam penelitian ini terdiri dari 2 jenis yaitu data primer dan data sekunder.Data primer diperoleh langsung dari responden baik melalui daftar pertanyaan maupun melalui wawancara.Sedangkan data sekunder berasal dari terbitan baik berupa data statistik, laporan penelitian, literatur, peraturan maupun terbitan lainnya.

\section{Teknik Pengumpulan Data}

Teknik pengumpulan data yang dipergunakan dalam penelitian ini meliputi : daftar pertanyaan, wawancara mendalam (indept interview), observasi dan dokumentasi. Daftar pertanyaan (questioner) ditujukan kepada petani gambir yang berada di Lareh Sago halaban.

\section{Teknik Analisis Data}

Teknik analisis data yang dipergunakan adalah : (1) analisis kualitatif dan (2) analisis kuantitatif.

1. Analisis Kualitatif dilakukan terhadap data kualitas berupa interprestasi atau penafsiran-penafsiran secara deskriptif terhadap persentase sistim strategi pemasaran yang dilakukan oleh petani gambir, serta kelembagaan yang berperan dalam pemasaran pertanian.

2. Analisis kuantitatif dilakukan terhadap data kuantitas terhadap tingkat penjualan yang di dapatkan serta keuntungan yang di capai, dengan melakukan analisis finansial (tingkat keuntungan, $\mathrm{R} / \mathrm{C}$ ratio)

\section{AnalisaPendapatan Usahatani gambir}

a. Menghitung Total Biaya Usahatani Gambir

Untuk menghitung total biaya menggunakan rumus menurut Noor (2007) yaitu:

$$
\mathbf{T C}=\mathbf{T F C}+\mathbf{T V C}
$$

Keterangan: $\quad \mathrm{TC}($ Total Cost)

$T C=$ Total Biaya Produksi $(\mathrm{Rp})$

TFC $($ Total Fixed Cost $)=$ Biaya Tetap $(\mathrm{Rp})$ TVC (Total Variable Co $=$ Biaya Variabel (RP)

Biaya yang dimaksud dalam penelitian ini adalah biaya operasional tidak termasuk biaya investasi tanaman.

\section{b. Menghitung Penerimaan Usahatani Gambir}

Untuk menghitung penerimaan pada usahatani gambir menggunakan rumus menurut Noor (2007) yaitu :

$$
\mathbf{T R}=\mathbf{P} \times \mathbf{Q}
$$

Keterangan :

$\mathrm{TR}($ TotalRevenue $)=$ Total penerimaan $(\mathrm{Rp})$ $\mathrm{P}($ Price $)=$ Harga produksi $(\mathrm{Rp})$ $\mathrm{Q}($ Quantity) $=$ Jumlah Unit Produksi $(\mathrm{Rp})$

\section{c. Menghitung Pendapatan Usahatani Gambir}

Pendapatan usahatani gambir merupakan hasil pengurangan antara total penerimaan dengan total biaya dengan rumus menurut Noor (2007) yaitu :

$$
\mathbf{\Pi}=\mathbf{T R}-\mathbf{T C}
$$

Keterangan :

$\Pi($ profit $)=$ Pendapatan $(\mathrm{Rp})$

$\mathrm{TR}($ TotalRevenue $)=$ Total penerimaan $(\mathrm{Rp})$ $\mathrm{TC}($ Total Cost $)=$ Total Biaya $(\mathrm{Rp})$

\section{d.Analisis R/C Ratio}

Analisis R/C Ratio digunakan untuk menentukan kelayakan usahatani yang dilakukan yang merupakan perbandingan antara total penerimaan dan biaya total selama periode penelitian dengan rumus sebagai berikut :

Rumus 
R/C Ratio : $\quad$ TR

$\overline{\mathrm{TC}}$

Keterangan :

$\mathrm{R} / \mathrm{C}$ ratio $=$ Penerimaan $/$ Biaya

$\mathrm{TR}($ Total Revenue $)=$ Total Penerimaan

TC $($ Total Cost $)=$ Total Biaya Produksi

Keterangan :

$\mathbf{R} / \mathbf{C}<\mathbf{1}$, Usaha tidak layak

$\mathbf{R} / \mathbf{C}=\mathbf{1}$, Usaha tidak untung dan tidak rugi

$\mathbf{R} / \mathbf{C}>\mathbf{1}$, Usaha layak untuk di usahakan

\section{Hasil Dan Pembahasan}

\section{Potensi Pengembangan Pertanian Gambir}

Produksi dari tanaman gambir di Kecamatan Lareh Sago Halaban sendiri didapatkan dari 3 Nagari dari total 8 Kenagarian. Yaitu Nagari Halaban, Nagari Ampalu, dan Nagari Sitanang seperti terliht pada Tabel 1

Tabel 1 . Data Luas Lahan Yang Memiliki Potensi Untuk Di Tanaman Gambir

\begin{tabular}{llcc}
\hline No & $\begin{array}{l}\text { Luas } \\
\text { Tanam } \\
(\text { Ha) }\end{array}$ & $\begin{array}{l}\text { Luas } \\
\text { panen } \\
(\text { Ha) }\end{array}$ & $\begin{array}{l}\text { Potensi } \\
\text { luasan } \\
(\text { Ha) }\end{array}$ \\
\hline 1 & $\mathbf{1 4 4}$ & $\mathbf{6 2}$ & $\mathbf{1 . 0 0 0}$ \\
\hline $\begin{array}{l}\text { Sumber }: \text { BPP } \\
\text { Halaban 2020 }\end{array}$ & Kecamatan & Lareh Sago
\end{tabular}

Tabel 1 memperlihatkan tanaman gaambir di daerah penelitian punya potensi yang baik untuk di kembangkan serta untuk dapat di kelola dengan baik. Pengelolaan usahatani yang baik akan mendatangkan keuntungan bagi petani yang akhirnya dapat meningkatkan pendapatan petani.

\section{Karakteristik Responden}

\section{a. Umur}

Kemampuan untuk melakukan kgiatan usahatani tani salah satunya di tentukan dengan tingkatan umur, dimana orang yang masih muda mempunyai kemampuan lebih baik dalam melakukan usaha. Tingkatan umur petani responden pada penelitian ini dikelompokkan menurut Departemen Kesehatan RI 2009 berdasarkan tingkatan produktifitasnya yang akan di sajikan secara rinci pada Tabel 2 berikut ini.

Tabel 2. Klasifikasi responden berdasarkan umur di Kecamatan Lareh Sago Halaban

\begin{tabular}{|c|c|c|c|}
\hline $\begin{array}{l}\mathbf{N} \\
\mathbf{O}\end{array}$ & $\begin{array}{l}\text { Interval } \\
\text { Umur } \\
\text { (Th) }\end{array}$ & $\begin{array}{c}\text { Jumah } \\
\text { Petani (Org) }\end{array}$ & $\begin{array}{c}\text { Persentas } \\
\text { e }(\%)\end{array}$ \\
\hline 1 & $(25-45)$ & 11 & 23,4 \\
\hline 2 & $(46-65)$ & 26 & 55,3 \\
\hline 3 & $(65+)$ & 10 & 21,3 \\
\hline & Total & 47 & 100 \\
\hline
\end{tabular}

Sumber :Data Primer Diolah 2021

\section{b. Pendidikan}

Tingkat pendidikan dari responden sebagian besar pada tingkat pendidikan SMA $(35,13 \%)$ dan yang terkecil yaitu pada tingkat sarjana yaitu $8,11 \%$ seperti Tabel 3 berikut:

Tabel 3. Tingkat Pendidikan Petani Gambir Di Kecamatan Lareh Sago Halaban

\begin{tabular}{llcr}
\hline No & $\begin{array}{l}\text { Tingkat } \\
\text { pendidikan }\end{array}$ & Jumlah & $\begin{array}{c}\text { Persentasi } \\
(\%)\end{array}$ \\
\hline 1 & SD & 12 & 25,5 \\
2 & SMP & 14 & 29,8 \\
3 & SMA & 18 & 38,3 \\
4 & SARJANA & 3 & 6,4 \\
\hline & Total & $\mathbf{4 7}$ & $\mathbf{1 0 0}$ \\
\hline
\end{tabular}

Sumber :Data primer diolah 2021

\section{c. Luasan Lahan}

Luas lahan yang diusahakan oleh Petani responden untuk usahatani gambir sebagian besar memiliki luasan lahan hanya 1 Ha yang masih terus di produksi. Responden yang memiliki luasan lahan 0-1 Ha sebanyak 23 orang dengan persentase $51,35 \%$, responden yang memiliki luasan lahan 1-2 Ha sebanyak 14 orang dengan persntase $27,03 \%$, responden yang miliki luasan lahan 2-3 Ha sebanyak 10 orang dengan persentase 21,62\% seperti Tabel 4 . 
Tabel 4 . Klasifikasi Luasan Lahan Petani Gambir di Kecamatan Lareh Sago Halaban

\begin{tabular}{cccc}
\hline No & $\begin{array}{c}\text { Luasan } \\
\text { Lahan } \\
\text { (Ha) }\end{array}$ & $\begin{array}{c}\text { Jumlah } \\
\text { Petani } \\
\text { (Orang) }\end{array}$ & $\begin{array}{c}\text { Persentase } \\
(\boldsymbol{\%})\end{array}$ \\
\hline 1 & $0-1$ & 23 & 51,35 \\
2 & $1-2$ & 14 & 27,03 \\
3 & $2-3$ & 10 & 21,62 \\
\hline & Total & $\mathbf{4 7}$ & $\mathbf{1 0 0}$ \\
\hline
\end{tabular}

Sumber :Data Primer Diolah 2021

\section{d. Sistim Pemasaran Pada Produk Gambir}

Pemasaran gambir yang di lakukan hanya berada pada rantai pedgaang pengumpul (Toke) yang datang ke tempat petani. Hal inimembuat harga pasar yang terjadi hanya di tentukan oleh toke, yang mengakibatkan petani tidak mempunyai posisi tawar dalam menentukan harga sehingga harga yang diterima petani tetap dibawah kendali toke (pedagang pengumpul). Saat ini petani gambir belum mampu menembus rantai pemasaran pedagang besar,

Untuk meningkatkan pendapatan petani seharusnya petani mempunyai posisi tawar yang baik dalam menentukan harga. Dari hasil penelitian inididapatkan bahwa informasi pasar selalu didapatkan oleh petani gambir, namun tidak bisa mendapatkan harga yang baik, karena kemampuan petani hanya bisa menjual kepada toke (Pedagang pengumpul) yang datang ke tempat petani gambir. Penyediaan tempat dan informasi pemasaran merupakan strategi yang penting bagi petani dalam mendapatkan pasar yang efisien (Elida, S, 2011).

Saluran pemasaran yang di lalui oleh petani gambir tidak dapat mem[erlihatkan seberapa besar margin yang di terima oleh pedagang, karena pedagang pengumpul lansung menjual kepada pedagang untuk di lakukan pemilihan mutu produk gambir. Harga yang di terima petani gambir di daerah penelitian cukup baik karena mutu gambir yang dihasilkan juga baik, namun tetap dintentukan oleh pedagang.

\section{Peran kelembagaan pada pemasaran produk gambir}

Lembaga pemasaran adalah badan usaha atau individu yang menyelenggarakan aktivitas pemasaran, menyalurkan jasa dan produk pertanian kepada konsumen akhir serta memiliki jejaring dan koneksitas dengan badan usaha dan atau individu lainnya.

Dengan adanya kelembagaan petani ekonomi masyarakat pedesaanakan terbantu dalam mengatur hubungan pemilik input dalam menghasilkan output ekonomi desa serta dalam mengatur distribusi tersebut. Manajemen usaha yang meliputi manajemen proses, keuangan, SDM dan pemasaran perlu di lakukan untuk efisiensi dan efektivitas produksi (Bismala, L., 2016).

Lembaga pemasaran yang berfungsi di daerah penelitian hanya ada pedagang pengumpul, sementara banyak jalurdalam pemasaran yang lain yang harusnya bisa berperan dalam meningkatkan penjualan petani gambir. Lembaga ini tidak dapat berfungsi di karenakan petani tidak memiliki akses terhadap pasar lainnya.Akibatnya harga ditingkat petani ditentukan oleh pedagang pengumpul saja.

Kelembagaan petani umumnya dijalankan dengan mengedepankan kepentingan sekelompok orang maupun kelompok tertentu, sementara petani kecil masih memiliki akses yang terbatas (Yuniati, S., Susilo, D.,\& Albayumi, F, 2017). Penguatan kelembagaan bertujuan untuk meningkatkan akses petani terhadap sumber daya yang ada baik untuk akses input produksi maupun pemasaran. Kelembagan petani harus di tempatkan sebagai sarana untuk mewujudkan harapan, keinginan dan kebutuhan petani. Kelembagan petani harus di tempatkan sebagai sarana untuk mewujudkan harapan, keinginan dan kebutuhan petani, peningkatan kapasitas kelembagaan petani 
di lakukan melalui penyuluhan dengan memotivasi petani dengan muatan content area untuk penguatan kapasitas individu (Anantanyu,S., 2011).

\section{Analisis Pendapatan Usahatani Gambir}

Dari hasil perhitungan data didapatkan rata-rata pendapatan petani gambir di Kecamatan Lareh Sago Halaban adalah sebesar Rp.2.000.366 dengan ratarata luas lahan 1,7 Ha.

\section{a. Analisis Kelayakan Usahatani Gambir (R/C) \\ Dari hasil perhitungan biaya} usahatani gambir di Kecamatan Lareh Sago Halaban didapatkan biaya variable, biaya tetap.Biaya variabel didapatkan dari biaya tenaga kerja, penyiangan danbiayapengolahan. Biaya tetap didapatkan dari biaya penyusutan alat dan biaya operasional lainnya dengan rincian biaya seperti terlihat pada Tabel 5 berikut.

Tabel 5. Rata-rata total biaya operasional usahatani gambir

\begin{tabular}{cccc}
\hline $\begin{array}{c}\text { N } \\
\text { o }\end{array}$ & Jenis Biaya & $\begin{array}{c}\text { Jumlah } \\
\text { /6 bulan } \\
\text { (Orang) }\end{array}$ & $\begin{array}{l}\text { Jumlah/bl } \\
\mathbf{n}\end{array}$ \\
\hline 1 & Penyusutan & 592,000 & 98.666 \\
2 & Penyiangan & $3.205,000$ & 534.167 \\
& & 13.250 .00 & \\
& Pengolahan & 0 & 2.208 .333 \\
3 & Pemeliharaa & 436.667 \\
4 & n & \multicolumn{3}{c}{2.620 .000} \\
\hline \multicolumn{4}{c}{ Tota67.000 } \\
\hline
\end{tabular}

Sumber :Data Primer Diolah 2021

Hasil perhitungan biaya yang dikeluarkan oleh petani gambir di Kecamatan Lareh Sago Halaban Selama 1 Periode panen atau 6 bulan dengan total Rp.19.667.000 dan selama 1 bulannya di keluarkan sebesar Rp.3.277.834.

\section{b. Produksi Usahatani Gambir}

Hasil perhitungan dari usahatani gambir di kecamatan Lareh Sago Halaban didapatkan produksi dengan rata-rata total produksi sebanyak 555,6 $\mathrm{Kg}$ selama satu periode panen dengan rata-rata luasan lahan seluas 1,7 Ha.

\section{c. Penerimaan Usahatani Gambir}

Dari hasil perhitungan usahatani gambir di Kecamatan Lareh Sago Halaban bahwa total produksi rata-rata petani gambir sebanyak $\pm 555,6 \mathrm{Kg}$ gambirdikalikandengan harga penjualan gambir sebesar Rp.57.000 didapatkan hasil penerimaan rata-rata petani gambir di Kecamatan Lareh Sago Halaban sebesar Rp.31.669.200 selama satu periode panen atau 6 bulan dan penerimaaan selama satu bulannya sebesar Rp.5.278.200.

\section{d. Rata-rata Pendapatan Petani Gambir}

Dari hasil perhitungan didapatkan rata-rata pendapatan petani gambir di Kecamatan Lareh Sago Halaban adalah sebesar Rp.1.218.100 dengan rata-rata luas lahan 1,7 Ha. Pendapatan ini ini didapatkan dari penerimaan di kurangi biaya biaya dengan rincian sebagai berikut:

$\Pi=5.278 .200-3.277 .833$

$=2.000 .367 / \mathrm{Bln}$

Keterangan :

$\Pi($ profit=Rp.2.000.367 / Bln

$\mathrm{TR}($ Total Revenue $)=$ Rp. 5.278.200 / Bln

$\mathrm{TC}($ Total Cost $)=\mathrm{Rp} .3 .277 .833 / \mathrm{Bln}$

\section{e. Analisis Kelayakan Usahatani Gambir (R/C)}

Berdasarkan hasil analisis kelayakan usahatani Gambir di Kecamatan Lareh Sago Halaban didapatkan R/C Ratio sebesar 1,6 (>1), yang berarti termasuk dalam katogori layak untuk diusahakan.

Nilai R/C ratio > 1 yang didapatkan dalam usahatani gambir di Kecamatan Lareh Sago Halaba disebabkan karena usahatani yang dijalankan tersebut sudah berjalan lama dan hanya membutuhkan biaya operasional yang tidak terlalu besar 
seperti biaya penyusutan alat dan penyiangan. Untuk biaya lain seperti pemupukan tidak ada karena tidak melakukan pemupukan dan hanya menggunakan pupuk yang berasal dari daun sisa kempaan saja. Sehinga biaya produksinya relatif kecil yang menyebabkan $\mathrm{R} / \mathrm{C}$ ratio lebih besar dari 1 . Walaupun secara kenyataan nilai penerimaan petani gambir masih jauh di bawah upah Minimum provinsi yang menjadi dasar dalam kelayakan hidup masyarakat di wilayah tersebut.

\section{f. Analisis Keberlanjutan Usahatani Gambir \\ Keberlanjutan usahatani gambir ini dilihat dari bebrapa dimensi \\ 1.Dimensi sosial ekonomi}

Keberlanjutan usahatani akan terjadi apabila kebutuhan petani tercukupi dengan usahatni yang di lakukan. Hasil penelitian ini menunjukan bahwa keberlanjutan usahatani tidak dapat tercapai kalau tingkat pendpaatan petani gambir hanya sebesar Rp. 2.000.367/ Bulan. Pendapatan ini lebih rendah dari Upah Minimum Provinsi yang di terima oleh petani yaitu sebesar 2.484.041. Kalau tingkat harga yang di terima petani tidak dapat ditingkatkan maka petani akan beralih kepada usahatani lain yang mampu memenuhi kebutuhan hidupnya.

\section{Dimensi Kelayakan Usaha}

Hasil dari kelayakan usaha sebenarnya usahatani ini layak untuk di usahakan namun dengan berbagai keterbatasan dan pengurangan terhadap penggunaan faktor produksi. Petani hanya melakukan pemupukan dan tidak melakukan pemeliharaan sehingga biaya yang di keluarkan juga berkurang.

Keberlanjutan usahatani gambir ini kalau di lihat dari nilai kleyakan $\mathrm{R} / \mathrm{C}=1$ Layak, artinya cukup baik untuk keberlanjutannya, Keberlanjutan usahatani ini juga di pengaruhi dengan harga yang di terima petani semakin tinggi harga yang di terima petani akan meningkatkan pendapatan petani.

\section{Diemnsi budidyara dan teknologi}

Hal lain yang perlu di tingkatkan adalah perluasan tanaman gambir sehingga akan memberikan peningkatn produksi dan pendapatan, begitu juga dengan teknik budidaya yang di lakukan perlu pemeliharaan terhadap komoditi gambir agar produksi meningkat. Kalau dari dimensi budidaya dan teknologi masih kurang karena masih memakai teknologi yang sangat sederhana dan sulit untuk berkembang. Hasil penelitian Pawiengla,A.A, Yunita, S, Adenan, M (2020), Pada komoditi kopi Juga menyatakan bahwa kelembagaan juga punya dimensi yang kurang untuk keberlanjutan usahatani, karena hampir keseluruhan dimensi yang ada kurang keberlanjutan usahatani.

\section{Dimensi Kelembagaan}

Hal lain yang juga menentukan keberlanjutan usahatani gambir ini di tentukan juga peran kelembagaan yang ikut membantu baik dalam pemasaran maupun sarana penunjang dalam kegiatan berusahatani gambir. Dimensi ini kurang baik untuk keberlanjutan usahatani gambir ini terutaman kelembagaan pemasaran.

\section{Kesimpulan}

Berdasarkan hasil penelitian di Kecamatan Lareh Sago HalabanKabupaten 50 Kota didapatkan kesimpulan sebagai berikut :

1. Pendapatan rata-rata petani gambir di Kecamatan Lareh Sago Halaban Kabupaten 50 Kota sebesar Rp. 2.000.100/Blndengan rata-rata luasan 1,7 Ha.

2. Peran kelembagaan belum memperlihatkan fungsi yang baik dan efektif, sehingga petani tidak punya posisi tawar terhadap harga gambir

3. Keberlnajutan usahatani gambir tidak dapat di lakukan kalau pendapatan 
petani masih terus berada di bawah standar Upah Minimum Provinsi.

\section{Daftar Pustaka}

Anantanyu,S,. (2011). Kelembagan petanidan strategi pengembangan kapasitas. SEPA, Vol 7(2) : 102-109

Bismala, L., (2016). Model manajemen Usaha Mikro Kecil dan Menengah ( UMKM) untuk meningkatkan efektivitas Usaha Kecil dan menegah. Jurnal entrepreneur dan Endtrepreneurship, Vol 5(1).

Dhalimi, A. 2006. Permasalahan Gambir di Sumatera Barat dan alternatif pemecahannya. Perspektif, Vol 5, No 1: 46-51

Elida, S. 2011. Strategi pemasaran gambir Kabupaten Kampar. Jurnal Sosial Ekonomi Pembangunan, Tahun I No 3

Hosen, N. 2017. Profil sistem usaha pertanian gambir di Sumatera Barat. Jurnal Penelitian Pertanian Terapan. Vol 17(2): 124-131

Irvanto, O \& dan Sujana (2020). Pengaruh Design produk, pengetahuan produk, dan kesadaran merek terhadap minat beli produk eiger ( Survey Komunitas Pecinta Alam di Kota Bogor). Jurnal Ilmiah Manajemen Keatuan, Vol 8(2) : 105-126

Nasution, A.H. 2015. Sistem Pemasaran gambir di Sumatera Barat (Kasus) di Kecamatan kapur IX Kabupaten Lima puluh kota. SEPA. vol 12, No $1: 1-10$

Nasrul, W,. Zulmardi., Indrayani, T. 2019. Kinerja Kelembagaan Pasar gambir. CV Insan Cendikia mandiri. Sumatera Barat

Pawiengla,A.A, Yunita, S, Adenan, M. 2020. Analisis keberlanjutan usahatani Kopi rakyat di Kecamatan Silo Kab Jember. Jurnal Ekononmi Pertanian dan Agribisnis ( JEPA), Vol 4, (4) : 701-714

Sukirno, S. 1994. Pengantar Ekonomi Makro. PT Raja Grasindo Persada. Jakarta
Untari, D dan Fajariana, D.,E ( 2018). Strategi pemasaran melalui media sosial instagram( Studi deskriptif padaakun @ subur_batik). Widya Cipta, vol 2(2) : 271-278

Yahono JT. 2014. Analisis pendapatan usahatani dan pemasaran gambir. Buletin penelitian tanaman rempah dan obat. Vol 15, No 2. ISSN. 02150824

Yuristia, R. 2017. Pemasaran gambir di kenagarian Manggilang Kecamatan Koto baru Kab Lima puluh Kota. Jurnal Pertanian Faperta UMSB, Vol 1. No

Yuniati, S., Susilo, D.,\& Albayumi, F, (2017). Penguatan Kelembagaan dalam upayameningkatkan kesejahteraan petani tebu. Prosididng Seminar Nasional dan Call For Paper Ekononmi dan Bisnis ( SNAPEREBIS 2017). Jember e proceeding: 498-505. ISBN : 978-602-5617-010. 